\title{
Violência contra a criança
}

\author{
Violence against children
}

\section{Lucia Belina Rech Godinho ${ }^{[a]}$, Vera Regina Röhnelt Ramires ${ }^{[b]}$}

[a] Mestre em Psicologia Clínica pela Universidade do Vale do Rio dos Sinos (UNISINOS), professora do Centro Universitário La Salle (UNILASALLE), Canoas, RS - Brasil, e-mail: luciarech@terra.com.br

[b] Doutora em Psicologia Clínica pela PUCSP, professora, pesquisadora e coordenadora do Programa de Pós-Graduação em Psicologia da Universidade do Vale do Rio dos Sinos (UNISINOS), Porto Alegre, RS - Brasil, e-mail: vramires@unisinos.br; veraramires@terra.com.br

\section{Resumo}

O objetivo do presente estudo é contribuir para a compreensão da violência no ambiente familiar, especificamente no que diz respeito à infância, constituindo-se como uma revisão teórica sobre o tema. Com base numa consulta realizada a livros e artigos, discute-se a violência contra a criança através da história e a proteção dos seus direitos. Aborda-se a aplicação de medidas disciplinares ao longo do tempo, bem como a compreensão acerca das atitudes relacionadas ao que pode ser denominado hoje como maus-tratos e violência contra a criança. A infância nem sempre foi compreendida da forma como a vemos hoje. Os castigos, as humilhações e até mesmo o assassinato de crianças foram tolerados por longos períodos na história. Os pais parecem ter tido soberanamente o poder de vida e morte sobre seus filhos. As mudanças em relação a essa perspectiva ocorreram principalmente nos dois últimos séculos. A partir de então, progressivamente, o relacionamento entre pais e filhos passou a ser permeado por atitudes mais afetivas, iniciando assim significativas mudanças que coincidiram com o estudo científico da infância. Observou-se importante evolução no âmbito do Direito, no sentido de proteger os direitos da criança, que passaram a ser reconhecidos. Constata-se, no entanto, que apesar de todas as medidas no sentido de proteção e garantia dos direitos, a violência contra a infância continua ocorrendo na realidade contemporânea.

Palavras-chave: Violência. Infância. História. Direitos da criança. 


\begin{abstract}
The purpose of the present study is to contribute to understanding violence in a family environment, especially in terms of childhood, and is formulated as a theoretical review of the theme. Based on book and article consultations, violence against children is looked at throughout history along with the protection of their rights. The application of disciplinary measures over time is approached, along with an understanding surrounding attitudes related to what can today be classified as abuse and violence against a child. Childhood was not always understood in the same manner it is today. The punishment, humiliation and even murder of children were tolerated over extended periods of history. Parents seem to have had supreme power over the life and death of their children. Changes in relation to this perception occurred mainly over the last few centuries. From then on, the relationship between parents and children became progressively permeated by more devoted attitudes, thus initiating significant changes that coincide with the scientific study of childhood. An important evolution is noted in terms of Law, in the sense of protecting children's rights, which had been recognized. However, it is shown that in spite of all the measures taken in terms of protection and a guarantee of rights, violence against children continues in our contemporary reality.
\end{abstract}

Keywords: Violence. Childhood. History. Children's rights.

\section{Introduçáo}

Diariamente, inúmeras notícias são veiculadas nos meios de comunicação informando sobre crianças vítimas de violência das mais diversas formas. Algumas dessas informações trazem dados chocantes capazes de gerar perplexidade e estarrecimento em quem as acessa. A violência, direta ou indiretamente, parece atingir a todas as pessoas (Schraiber, D’Oliveira \& Couto 2006), não escolhendo classe social, grau de instrução, gênero, lugar e nem mesmo idade para se manifestar. Existem casos que ganham notoriedade e ocupam com destaque os noticiários durante semanas, enquanto outros passam quase despercebidos. Os casos que ganham repercussão na mídia levam a refletir e a levantar questionamentos sobre o número de crianças anônimas que diariamente são vítimas silenciosas e indefesas da violência. Provavelmente, existem milhares de crianças que rotineiramente são submetidas à agressividade de adultos, que podem ter sido também vítimas de outras violências durante seu desenvolvimento. Tal ocorrência tem sido denominada pela literatura especializada como repetição do ciclo transgeracional (Grienenberger, Kelly, Kristen \& Slade, 2005; Shechter et al., 2005; Weber, Viezzer, Brandenburg, \& Zocche, 2002).

A violência tem sido objeto de estudo e reflexão pelas mais variadas áreas do conhecimento, como a história, sociologia, antropologia, psicologia e medicina. Atualmente, pode-se encontrar vasta produção de literatura também nos campos da enfermagem, odontologia, fonoaudiologia, entre outros. De forma geral, a área da saúde apresenta boa parte das pesquisas e publicações sobre a violência doméstica na infância. Há um reconhecimento crescente acerca da importância da prática da interdisciplinaridade como um caminho para a compreensão e o tratamento das vítimas de violência (Carneiro, 1999; Neves \& Romanelli, 2006).

Nas últimas duas ou três décadas, parece estar surgindo uma certa mobilização de órgãos governamentais e também dos profissionais da área da saúde no sentido de se voltarem para a compreensão e abordagem do problema da violência, mais especificamente da violência doméstica contra a criança e o adolescente (Romaro \& Capitão, 2007). O presente trabalho visa a contribuir para a compreensão da violência no ambiente familiar, constituindo-se como uma revisão teórica sobre o tema. Foram consultados livros e artigos, sendo que os artigos foram identificados nas bases de dados Scielo, BVS, INDEXPSI, a partir de 1999. Os descritores utilizados foram: criança, infância, maus-tratos, maltrato, violência, violência e crianças, violência e psicanálise, violência e psicoterapia. Foram selecionados livros e artigos que abordassem a questão da violência contra a criança na contemporaneidade e também ao longo da história e em diferentes culturas. O material selecionado foi organizado em duas categorias apresentadas a seguir: 
a violência contra a criança como um fenômeno antigo e contemporâneo e a proteção dos direitos da criança ao longo do tempo até os dias atuais.

\section{Violência na infância: fenômeno antigo e contemporâneo}

A violência contra a criança não é um fato recente (Del Priori, 2004; Pires \& Miyazaki, 2005). É um fenômeno que surgiu com o homem, tão antigo quanto a humanidade, e não se apresenta de forma isolada, pois envolve uma grande variedade de fatores biopsicossociais (Reyes, 2003). "Não poupes ao menino a correção: se tu o castigares com a vara, ele não morrerá; castigando-o com a vara salvarás sua vida da morada dos mortos" (Bíblia Sagrada, Provérbios 23). Essa citação bíblica, assim como inúmeros outros ditos populares sobre o tema, indica que o uso da punição e da violência para disciplinar crianças é um método que remonta a milênios.

Por vários séculos, a imagem da infância foi aquela expressa por Santo Agostinho (354-430 d.C.), que afirmava não existir inocência infantil, pois a criança traria o pecado original do ventre materno (Weber, Viezzer \& Branderburg, 2004). Santo Agostinho justificava a violência física e o castigo corporal pelo argumento da corrupção moral da infância (Weber et al., 2002).

Na compreensão de Ariès (2006), o sentimento de infância tal como o conhecemos hoje não existia na sociedade medieval. Não se tinha consciência da particularidade infantil que distingue a criança do adulto. Com o passar do tempo a situação foi se modificando. Visava-se então a conhecer a criança para discipliná-la, corrigi-la, perceber suas fraquezas e humilhá-la para ser "melhorada".

Day et al. (2003) informam que, quanto mais regressarmos na história, maiores as chances de deparar-nos com a falta de proteção à criança, aumentando a probabilidade de que tenham sido abandonadas, assassinadas, espancadas, aterrorizadas eabusadas física e sexualmente. Não faltam exemplos. No Oriente Antigo, o Código de Hamurábi (1728/1686 a.C.), art. 92, previa o corte da língua do filho que ousasse dizer aos pais adotivos que eles não eram seus pais, assim como a extração dos olhos do filho adotivo que aspirasse a voltar à casa dos pais biológicos. Os mesmos autores referem que a punição aplicada ao filho que batesse no pai era ter a mão decepada. Em Roma, a Lei das XII Tábuas, entre os anos 303 e 304, permitia ao pai cometer o filicídio, caso o filho nascesse com alguma deformidade. Para isso, necessitava de autorização concedida mediante julgamento de cinco vizinhos.

Rascovsky (1975) afirma que não existe no mundo nenhum processo sociocultural que não imponha aos filhos sanções restritivas ou ritos de iniciação que podem até culminar em assassinatos de maneira ostensiva ou camuflada. Revela que, em muitas sociedades, sempre se cumpriram determinadas cerimônias para que o recém-nascido fosse aceito na vida. Exemplifica que, entre os gregos, a cerimônia de aceitação ocorria no quinto dia do nascimento, quando a criança era levada pela babá até o coração ancestral, para ser consagrada e receber um nome. Se o pai não desejasse tal filho, deveria abandoná-lo durante a cerimônia que se denominava amphidroma. $\mathrm{Na}$ Frísia, conta o autor, o pai só podia matar ou abandonar a criança antes que ela comesse, pois se considerava que ao lhe dar comida, o pai reconhecia seu direito à vida. Entre os primitivos escandinavos, os vikings mostravam uma lança ao varão recém-nascido. Se a criança a segurava, permitiam-lhe viver. Outras crianças eram também submetidas a uma espécie de batismo. Imediatamente após o nascimento, o bebê era colocado sobre os joelhos do pai ou no chão, em diante do pai. Se decidisse que a criança devia viver, o pai segurava-a nos braços, jogava-lhe água, dava-lhe um nome e um presente. Só então a alimentavam. Se a criança não era levantada pelo pai, era sacrificada imediatamente. Depois de alimentada e batizada, a criança tinha direitos adquiridos e tornava-se ilegal sacrificá-la.

A vida de uma criança muitas vezes dependia de tais cerimônias. Rascovsky (1974) informa que tais costumes permaneceram em vigência na Suécia até 1734, na Noruega até 1854 e na Dinamarca até 1857. O autor ainda faz menções à situação de países como a Índia, onde se calcula que até o século passado seis sétimos da população praticava sistematicamente o filicídio de meninas. Na China, por razões econômicas, era também frequente matar meninas ou vendê-las como escravas. É provável que, em alguns grupos de chineses, o método hoje ainda seja utilizado como um primitivo controle de natalidade ou como forma de livrar-se de crianças débeis ou disformes. Portanto, parece que a matança de recém-nascidos foi considerada fato comum em muitas culturas e em várias épocas. 
Até por volta do século XVII, não existiam muitas restrições quanto à prática do infanticídio (Ariès, 2006; Postman, 1999), entendendo-se que o termo se refere ao assassinato de crianças em geral. Uma dessas formas de matança de crianças é o filicídio, que se refere especificamente ao crime de matar os próprios filhos (Rascovsky, 1974). O filicídio pode ser considerado como um fenômeno extremo da crueldade dos pais em relação aos filhos e apresenta-se como uma das manifestações da violência doméstica contra a criança (Telles, Soroka \& Menezes, 2008). Rascovsky (1975), referindo-se ao fenômeno, aponta que é inegável a tendência destrutiva dos pais em relação aos filhos e menciona que essa tendência pode ser inerente à condição humana.

Essas concepções têm conexões com as teorias de Freud ([1915]1987) sobre as pulsões de vida e de morte, segundo as quais o homem seria alguém dotado constitucionalmente da capacidade de amar e de odiar. O ódio é ainda mais antigo que o amor, postula o autor. Os indivíduos são capazes de se vincular e interagir impulsionados por motivações tanto sádicas quanto masoquistas. Uma referência explicita à questão da destrutividade aparece em Freud ([1920] 1987) ao demarcar o surgimento da segunda tópica e do dualismo pulsional: Eros (pulsão de vida) e Tânatos (pulsão de morte). Para ele, o impulso agressivo é derivado do instinto de morte. A partir dessa descrição, a menção à capacidade destrutiva do homem tem um papel cada vez mais proeminente na obra freudiana. O ódio se torna "um dos pólos do novo dualismo pulsional, como expressão da pulsão de morte" (Souza, 2005).

As concepções de Freud ([1915] 1987) e de Rascovsky (1974) parecem despertar uma clara resistência em nossa cultura. Exemplo disso seria o fato de que, por muito tempo, inexistiu na literatura a denominação da palavra filicídio, preferindo-se a utilização da denominação infanticídio até meados do século passado (Maltz et al., 2008). No entanto, o tema do filicídio está presente desde as mais remotas culturas. Tomemos o exemplo do mito hindu de Ganesha, filho de Shiva e Parvati, que se transformou num fantástico ser, metade menino, metade elefante, depois que teve sua cabeça decepada por seu pai. Ganesha se interpôs num conflito entre seu pai e sua mãe, e o pai, que ignorava a própria paternidade, cometeu o crime. Informado pela mãe do menino que era seu pai, tentou reparar seu ato. Colocou sobre o corpo do menino a cabeça do primeiro ser vivo que encontrou pela frente: um elefante (Goel, 2000). Talvez Ganesha seja o ancestral mais antigo da tragédia que envolve a rivalidade entre pais e filhos. O equivalente mais recente seria o mito de Édipo, retomado pela teoria freudiana para designar os impulsos amorosos e hostis que a criança nutre por seus pais, os quais foram denominados como Complexo Edípico (Freud, [1913] 1987).

A teoria não leva em conta, no entanto, o que um pai pode sentir em relação ao filho. Faimberg (2001) ressalta a necessidade de considerar que a tragédia de Sófocles ocorreu também em virtude de fatos transcorridos na vida de Laio, que fora antes expulso do reino de Tebas por comportamentos perversos, sendo assim amaldiçoado pelo rei de Pélope, que rogara que Laio nunca teria filhos ou, se os tivesse, morreria pelas mãos de um deles. O fato consumou-se depois que seu filho Édipo foi afastado dos pais justamente para evitar a profecia do oráculo que previra que o filho de Laio o mataria e casaria com sua mãe Jocasta. Antes disso, Laio, com o propósito de evitar tal destino, tenta matar seu filho, mandando pendurá-lo pelos pés num monte, o que lhe gerou uma deformidade perene, mesmo tendo sua vida salva por um pastor. Numa segunda versão, o desfecho para a história é igualmente cruel, pois Laio abandona seu filho no rio e ele é salvo pelas lavadeiras, sendo recolhido e adotado por Pólibo e Peribea. No confronto final, relata a literatura, quando Laio e Édipo se reencontram, o filho mata o pai em legítima defesa durante uma briga (Faimberg, 2001). Parece que o pano de fundo da tragédia edipiana consiste no fato de que o nascimento, a vida do filho e o seu crescimento põem em perigo a existência do pai, chegando a significar até mesmo a sua morte (Ramires, 1997). Portanto, Laio é descrito como um pai narcisista e filicida (Faimberg, 2001).

$\mathrm{Na}$ compreensão de Canevacci (1976, p. 36), o obscuro presságio de Laio é a ameaça inconfessada que todo pai experimenta diante do filho. A crise fatal de Laio tem sua origem na condenação histórico-cultural que toda geração paterna experimenta em relação a si mesma, como consequência da pura e simples presença de um filho, ou seja, a sucessão na vida, nos bens e no sexo. Para o mesmo autor, a ambivalente relação de amor e ódio oculta uma realidade bem diversa, "um terror angustiado, profundo, irracional" que a geração dos pais experimenta inconscientemente diante dos filhos que estão emergindo para a vida, prenunciando a caducidade 
da geração anterior. "O Complexo de Édipo é o produto do terror autoritário de Laio negado, invertido e projetado".

Nessa retomada do mito edipiano, podemos pensar o quanto o filicídio/infanticídio e o parricídio estão implicados. Tanto o parricídio quanto o infanticídio parecem ser representantes da rivalidade narcísica, afirma Faimberg (2001). A fantasia do parricídio aparece com clareza em Freud ([1913] 1987) ao descrever o totemismo, ${ }^{1}$ indicando que o animal totêmico é, na realidade, um substituto do pai - isto entra em acordo com o fato contraditório de que, embora a morte do animal totêmico seja proibida, sua matança, no entanto, é uma ocasião festiva. Ele é morto, festejado e pranteado, o que denota uma "atitude emocional ambivalente" (Freud, [1913] 1987, p. 169). O pai parece representar, nesse entendimento freudiano, um obstáculo ao anseio de poder do filho: ele é amado e admirado, mas também odiado. A ideia do parricídio parece conter uma conexão com a atitude filicida, pois parece estar presente uma culpa parental provocada "pela inveja em relação aos filhos e pelos atos de mortificação e assassinato decorrentes" (Rascovsky, 1974, p. 43).

Já Canevacci (1976, p. 33) apresenta uma compreensão mais ampla e afirma que a questão da morte está presente na própria constituição da família. "O fantasma da morte paira sobre a família", postula o autor, que entende que o fato ocorre tanto por conta do desejo de violência em relação ao pai quanto porque as imagens e o próprio conceito de morte se produzem pela primeira vez, na mente da criança, no âmbito familiar. Assim, a família se torna, consciente ou inconscientemente, o "foco das pulsões destrutivas e autopunitivas".

Rascovsky (1974,p. 9) argumenta que "não existe nada mais sinistro e nada mais intensamente negado do que o filicídio, tanto em suas formas ostensivas como em suas formas veladas". Entretanto, continua o autor, "ao lado das tendências filicidas, coexistem nos pais, em maior grau, os desejos ternos e amorosos, que permitem a sobrevivência do filho" (Rascovsky, 1974, p. 10).

Sobre o sacrifício de crianças, Rascovsky (1974, p. 7) refere-se a documentos históricos antigos e às lendas e mitos primitivos que chamam a atenção para a "universalidade do sacrifício filial". Na agricultura, por exemplo, o ritual do sacrifício de crianças era difundido para propiciar boas colheitas, afirma o autor. O mesmo dado é trazido por outros autores como Guerra (2001), que menciona a existência de crenças justificando o sacrifício de crianças em algumas culturas. Por exemplo, algumas tribos de índios mexicanos associavam o sucesso da colheita com o sacrifício de uma criança recém-nascida à época da semeadura. Muitas tribos de índios protegiam seus filhos, mas poderiam ser cruéis com filhos de inimigos, que eles engordavam, matavam e até comiam (Guerra, 2001; Pires \& Myiazaki, 2005).

Num outro exemplo de crueldade contra a criança, encontra-se uma referência a uma lei hebraica do século XIII a.C., que instruía os pais sobre como castigar filhos desobedientes e rebeldes. Se os pais tivessem dificuldades em tal tarefa, um conselho era solicitado para lidar com o filho problema, punindo-o e apedrejando-o até a morte (Santoro, 2002). Ariès (1992) refere que, no império greco-romano, o infanticídio era prática habitual - cabia ao pai aceitar ou não o recém-nascido. Se fosse rejeitado, dificilmente alguém acolhia o abandonado, que acabava morrendo. $\mathrm{O}$ autor refere-se ao termo "infanticídio tolerado", revelando que algumas vezes era praticado em segredo, camuflado sob a forma de acidentes ou pela submissão da criança à miséria. A vida da criança era considerada com a mesma ambiguidade que hoje se considera a vida de um feto. Parece que a vida de uma criança valia muito pouco (Ariès, 2006).

"No período que antecedeu o século XVIII, surge a utilização dos castigos, da punição física, dos espancamentos através de chicote, ferros e paus às crianças" (Day et al, 2003). Acreditava-se que as crianças poderiam ser moldadas de acordo com os desejos dos adultos. Na Inglaterra, em 1780, as crianças podiam ser condenadas por qualquer um dos mais de duzentos crimes cuja pena era o enforcamento. Somente no século XIX o filho passa a ser objeto de investimento afetivo, econômico, educativo e existencial. A partir do início do século $\mathrm{XX}$, a medicina e outras áreas do conhecimento começam a contribuir para a formação de uma nova mentalidade de assistência à criança, abrindo espaço para uma concepção de educação baseada

\footnotetext{
1 Doutrina ou sistema do totem que consiste na crença da existência de uma relação de afinidade ou parentesco com um animal (totem). O totem é um antepassado comum ao clã e do qual se espera proteção (Freud [1913] 1987).
} 
em fundamentos científicos (Ariès, 2006; Day et al, 2003; Postman, 1999).

Historicamente, portanto, a preocupação com a infância parece ser algo recente. Na sociedade medieval, que tomamos como ponto de partida, o sentimento de infância não existia, o que não quer dizer que as crianças não fossem negligenciadas, abandonadas ou desprezadas, explica Ariès (2006). Somente a partir do século XVII e XVIII é que elas foram se tornando numerosas (Ariès, 2006; Postman, 1999), com a diminuição da mortalidade infantil. Os autores afirmam que, antes disso, as crianças pareciam "invisíveis", havia uma evidente falta de interesse por elas. Era como se vivessem no anonimato. Rapidamente uma criança era substituída por outra, em virtude da morte precoce. Não havia literatura infantil, nem livros de pediatria, e parece que o destino de muitas crianças era morrer, geralmente afogadas, asfixiadas ou abandonadas. Recebiam cuidados especiais apenas em idade precoce e eram "paparicadas" apenas enquanto criancinhas pequeninas ou "coisinha engraçadinha" (Ariès, 2006). Assim que cresciam um pouco, já representavam força de trabalho e eram tratadas como adultos em miniatura.

Referindo-se aos métodos educacionais e à disciplina, Ariès (2006) buscou informações principalmente baseadas na rotina e na convivência de colégios franceses, no período compreendido entre o século XV e o século XVIII. O sistema educacional priorizava a vigilância constante, a delação, a espionagem mútua e a aplicação de castigos corporais. Tratava-se de uma disciplina humilhante: o chicote ficava a critério do mestre, não havia muita distinção e critério para submeter crianças e adolescentes aos castigos, pois "todas as crianças e todos os jovens, qualquer que fosse a sua condição, eram submetidos a um regime comum e eram igualmente surrados" (Ariès, 2006, p. 118). Na verdade, segundo o mesmo autor, foi por meio da mudança trazida pela escolarização que teve início o reconhecimento e a preocupação com essa etapa da vida, passando a família a ser um grupo significativo de referência, a quem competia cuidar e acompanhar as crianças, zelando pelo seu bem estar.

Para Postmann (1999), os "métodos educacionais" prevalentes até por volta dos séculos XVII e XVIII provavelmente equivaleriam ao que hoje denominamos como maus-tratos. Weber et al. (2002) confirmam essa ideia referindo que, por muito tempo, a noção de maus-tratos nem sequer era considerada.
Portanto, parece que a violência possui historicidade e leva a questionar sobre o valor da vida humana, afirmam Gomes, Deslandes, Veiga, Bhering e Santos (2002). O castigo físico e o infanticídio foram permitidos por lei durante muitos séculos (Postman, 1999), assim como a escravidão e a exploração do trabalho infantil foram toleradas e aceitas como prática comum (Pires \& Miyazaki, 2005).

A partir do século XVIII, surgiu uma preocupação mais ampla com o estudo da criança e com a necessidade de uma educação formalizada. Ainda assim, a disciplina nas famílias e na escola era exercida de forma violenta. Pode-se dizer que, por milhares de anos, predominou um total desconhecimento das características e peculiaridades da infância. Parece que essas atitudes passaram a sofrer mudanças somente a partir do estudo científico da criança (Ariès, 2006; Postman, 1999). No entanto, é possível afirmar que, até o início do século XX, as relações entre pais e filhos ainda eram ainda permeadas por agressões (Weber et al., 2002).

Somente a partir das novas concepções surgidas sobre a infância é que a criança passou a ser valorizada como um ser que necessita de cuidados e atenções especiais, havendo assim uma aproximação afetiva entre a criança e seus pais biológicos (Weber et al. 2004). Antes disso, por muito tempo, afirmam os mesmos autores, sua criação era, na maioria das vezes, delegada a pessoas alheias à família.

Sobre essa realidade em nosso país, Pires e Miyazaki (2005) trazem referências sobre o tratamento que era destinado a crianças abandonadas na cidade de São Paulo por volta do séc. XVIII, principalmente para crianças filhas de mães solteiras, viúvas ou extremamente pobres. Tais crianças eram chamadas de "os expostos". Em 1924, foi instalada na mesma cidade a Roda da Santa Casa, idealizada em Portugal, que tinha como objetivo evitar que as crianças fossem devoradas por cães quando abandonadas. A Roda possuía um cilindro oco de madeira que girava em torno do próprio eixo e tinha uma abertura, onde eram anonimamente colocadas as crianças. A mãe que abandonava seu filho batia na madeira e girava, avisando à portaria da Santa Casa, que, pelo lado interno da Roda, recolhia o abandonado. Neves e Romanelli (2006), discutindo o tema do abandono de crianças, informam que o Brasil foi o último país a abandonar as Rodas dos Expostos. Esse dispositivo foi utilizado no período que vai do séc. XVIII até por volta do ano de 1950, com o 
objetivo caritativo e religioso de abrigar crianças e recém-nascidos abandonados por seus familiares, lembrando uma herança trazida para a atualidade: a institucionalização de crianças como recurso imediato diante dos desajustes familiares (Neves \& Romanelli, 2006).

Indiscutivelmente, parece ser consenso que, contemporaneamente, a violência é reconhecida como um problema social e de saúde pública (Gomes, Junqueira, Silva, Junger, 2002; Pires \& Myiazaki, 2005; Sacramento \& Rezende, 2006; Schraiber et al., 2006; Tardivo, Junior \& Santos, 2005). A violência contra a criança se apresenta, desde os tempos primitivos até hoje, como um fenômeno cultural de grande relevância (Minayo, 2001), existindo famílias que ainda hoje se expressam de forma similar ao que prevaleceu por tantos séculos, ou seja, pelo abandono, pelos maus-tratos e pelo abuso, chegando ao extremo do assassinato de suas crianças (Maltz et al., 2008). Segundo Guerra (2001), a violência doméstica é um tipo de violência de natureza interpessoal, na qual se verifica uma transgressão do poder disciplinador e coercitivo do adulto. A violência pode ficar encoberta por longo período de tempo sem ser denunciada (Unicef, 2006).

"O tipo mais frequente de maus tratos contra a criança ou adolescente é a violência doméstica, que ocorre, na maioria das vezes, dentro dos lares ou no convívio familiar" (Pires \& Miyazaki, 2005, p. 44). Muitos desses episódios são encobertos e aparecem de forma camuflada como "acidentes", denunciando, assim, a falta de cuidados em relação às crianças (Gomes, Silva \& Njaine, 1999). De acordo com dados levantados pelo Unicef (2006), os acidentes e as agressões são a primeira causa de morte de crianças de 1 a 6 anos de idade no Brasil. Silva, Coelho e Caponi (2007) referem que existe alguma concordância na literatura quanto à presença da violência psicológica em praticamente todos os outros tipos de violência sofrida pelo sujeito no contexto familiar. De forma geral, parece que persiste ainda a ideia de que a punição corporal é uma prática educativa aceitável e, muitas vezes, considerada adequada (Cecconello, De Antoni \& Koller, 2003; Guerra, 2001; Weber et al., 2002).

Guerra (2001) e Tardivo et al. (2005) afirmam que o fenômeno da violência não é característico apenas das classes mais pobres - trata-se de um fenômeno universal que pode envolver pessoas de qualquer etnia ou classe social, além de várias gerações familiares. O cenário é a casa e os personagens desse triste enredo são os membros de sua própria família, uma vez que a violência é exercida na intimidade do lar que, ao estabelecer normas, valores e costumes, determina também como os indivíduos se relacionarão de acordo com a distribuição do poder (Unicef, 2005). Para Gomes et al. (2002), a busca pela explicação de por que as crianças são maltratadas encontra parcialmente a resposta na questão da repetição transgeracional e na sua influência sobre a educação dos filhos, pois parece que a situação presente revive o passado em termos de violência familiar.

A violência contra a criança pode representar um fator de risco ao processo do seu desenvolvimento, trazendo graves consequências para a vítima, implicando problemas de ajuste ao seu meio, perturbação da noção de identidade e outros distúrbios de personalidade (McDonald, Jouriles, Briggs-Gowan, Rosenfield, Carter, 2007; Tardivo et al., 2005). Evidencia-se uma gradativa consciência de que os maus-tratos contra crianças trazem frequentemente consequências negativas significativas àqueles que são vítimas, sendo um importante preditor de problemas comportamentais, especialmente os maus-tratos físicos e sexuais (Malik, Ward \& Janczewski, 2008; Pesce, 2009). Quanto mais precocemente a criança é submetida à violência, mais suscetível ficará aos efeitos desta (Sternberg, Lamb, Guterman \& Abbott, 2006). Crianças que experimentaram a violência na relação com seus cuidadores, em geral, têm uma história pessoal de problemas de apego, com ausência ou fragilidade nos vínculos (Lisboa \& Koller, 2000). A experiência pode levar a danos como autoestima baixa, dificuldade de manter vínculos afetivos, isolamento, agressividade, falta de confiança, dor emocional e ressentimento. Além disso, pode perpetuar o círculo vicioso, existindo a possibilidade de o agredido tornar-se o agressor. A agressão pode ser em relação ao outro ou a si próprio, pois as vítimas da violência possuem maior risco de cometer suicídio (Weber et al., 2002). Portanto, parece evidente que experiências adversas na infância surgem como fortes indicadores de problemas emocionais e físicos na vida adulta (Broad \& Wheeler, 2006).

Diante desse cenário, diversas áreas de conhecimento têm se mobilizado para a promoção do cuidado e a proteção de crianças e adolescentes no Brasil e no mundo. $\mathrm{O}$ assunto foi objeto de uma evolução importante, no âmbito do Direito, nas últimas décadas do século passado. Esse é o tópico abordado a seguir. 


\section{A proteção dos direitos da criança: A infância no âmbito do Direito}

A valorização da infância no âmbito do Direito foi muito tardia. Somente em 1959, com a promulgação da Declaração dos Direitos da Criança pela Assembleia Geral da Organização das Nações Unidas (ONU), a criança se tornou legalmente um sujeito de direitos (Weber et al. 2004). Considerando essa preocupação universal de proteção às crianças, poderíamos pensar sobre o artigo 37 , da Convenção dos Direitos da Criança, proferida pela Assembleia Geral da ONU de 1989: "Nenhuma criança será submetida à tortura ou a penas ou a tratamentos cruéis, desumanos ou degradantes" (Unicef, 2006). A Convenção implicou desdobramentos nos países-membros, no campo do Direito e da proteção de crianças e adolescentes. O Brasil não ficou de fora desse processo.

Em nosso país, identificam-se três correntes jurídico-doutrinárias em relação à proteção da infância, desde o século XIX (Pereira, 2000). A primeira delas, conhecida como a Doutrina do Direito Penal do Menor, preocupava-se especialmente com a delinquência, e baseava a imputabilidade no entendimento do "menor" a respeito da prática do ato criminoso. Posteriormente, passou a vigorar a Doutrina Jurídica da Situação Irregular, com o advento do Código de Menores de 1979, que foi marcado por uma política assistencialista fundada na proteção do menor abandonado ou infrator. As situações de perigo ou irregulares estavam associadas ao abandono material ou moral, considerando-se que poderiam conduzir o "menor" à criminalidade. Compreendia-se que tais situações irregulares, via de regra, eram consequência da situação irregular da família, principalmente da sua desagregação.

Marques (2000, p. 468) assinala o paternalismo das instâncias voltadas para a infância e a adolescência nessa Doutrina, já que a criança e o adolescente eram tomados como objetos de medidas de proteção, em uma perspectiva tutelar, receptores de uma prática assistencialista. Essa prática era tida "como benesse e, portanto, sem considerar seus direitos à convivência familiar e comunitária, à opinião, ao respeito e à dignidade".

A Doutrina Jurídica da Situação Irregular foi substituída pela Doutrina Jurídica da Proteção Integral, que passou a vigorar no Brasil a partir da Constituição Federal de 1988. O Código de Menores, da mesma forma, deu lugar ao Estatuto da Criança e do Adolescente (Lei 8.069, de 13 de julho de 1990). A Doutrina Jurídica da Proteção Integral teve suas bases no movimento de mobilização do início da década de 1980, marcado por intenso debate acerca da proteção da infância e da adolescência, conforme Pereira (2000).

O Brasil foi se alinhando, assim, às diretrizes e Documentos Internacionais de proteção da infância. Já em 1948 a Declaração Universal dos Direitos Humanos das Nações Unidas destacou, para as crianças, o "direito a cuidados e assistência especiais”. Em 1959, a Declaração Universal dos Direitos da Criança determinaria que a criança tem o direito de proteção especial de modo que possa se desenvolver física, mental, moral, espiritual e socialmente de forma saudável e normal, assim como em condições de liberdade e dignidade (Ramires \& Rodrigues, 2003).

Em 1989, no ano em que se comemorava 30 anos da Declaração Universal dos Direitos da Criança, foi aprovada por unanimidade a Convenção Internacional dos Direitos da Criança. O Brasil ratificou essa Convenção em 1990, por meio do Decreto 99.710, que assegura, em seu artigo 3.1, o seguinte: "todas as ações relativas às crianças, levadas a efeito por instituições públicas ou privadas de bem-estar social, tribunais, autoridades administrativas ou órgãos legislativos, devem considerar, primordialmente, o interesse maior da criança". Para Ramires e Rodrigues (2003), observou-se uma mudança de foco na legislação brasileira de proteção da infância, que se deslocou da exclusão e da repressão para a proteção com prioridade absoluta, que não é mais obrigação exclusiva da família e do Estado: é um dever social. Passa-se ao enfoque da inclusão social, da prevenção e da promoção do desenvolvimento integral da infância.

A Constituição Federal de 1988, em seu artigo 227, contempla o princípio do melhor interesse da criança, ao estabelecer que é dever da família, da sociedade e do estado assegurar à criança e ao adolescente o direito à vida, à saúde, à alimentação, à educação, ao lazer, à profissionalização, à cultura, à dignidade, ao respeito, à liberdade, e à convivência familiar e comunitária, além de colocá-los a salvo de toda forma de negligência, discriminação, exploração, violência, crueldade e opressão. O Estatuto da Criança e do Adolescente (ECA) incorporou esse artigo em seus dispositivos, especialmente ao considerar a 
criança e o adolescente como sujeitos de direitos e ao assumir a doutrina da proteção integral, assegurando assim os direitos fundamentais inerentes à pessoa humana (Ramires \& Rodrigues, 2003).

Essa perspectiva redireciona todas as questões relacionadas a crianças e adolescentes, tanto na esfera das políticas governamentais como nas decisões judiciais (Ramires \& Rodrigues, 2003). De uma postura mais assistencialista e punitiva ocorre o deslocamento para uma nova postura, voltada para cuidar, proteger e educar. Antes da Constituição Federal de 1988 e do ECA (1990), o atendimento à faixa etária abaixo dos 7 anos era de natureza assistencial, não educacional, e numa visão de saúde pública não universalizada, não havendo maior comprometimento do Estado com a infância. Após 1988, contudo, a nova legislação legitima o papel e o compromisso do Estado com as crianças.

Considerando a evolução da legislação de proteção da criança, parece que partimos de uma época remota em que os pais dispunham, de fato, do direito de vida ou morte sobre seus filhos. Evoluímos de leis que toleravam a humilhação, o espancamento e até o infanticídio para leis atuais que visam garantir o melhor interesse da criança, abrindo espaço para que ela seja escutada em suas necessidades. Observa-se que a literatura sobre as concepções de infância, de certa forma, também evoluiu. No entanto, a violência contra a criança atravessa os séculos. Cabe então questionar por que, apesar de todo esse conhecimento, as medidas de proteção das crianças ainda falham. A realidade contemporânea nos mostra que, em pleno século XXI, ainda ocorrem verdadeiras barbáries contra a infância.

\section{Consideraçóes finais}

Como foi constatado na revisão realizada, a violência contra a infância é inegável. O fenômeno existe e parece que sempre existiu, atravessando séculos. O significado da infância é que mudou - não foi sempre o mesmo ao longo da história e em diferentes culturas. A literatura mostra que os pais mantiveram, em diferentes tempos e lugares, soberanamente, o poder de vida e morte sobre seus filhos. Por longo tempo, foram permitidas e toleradas situações de maus-tratos e até mesmo o assassinato de crianças.

Uma das explicações para tais fatos reside no reconhecimento da porção agressiva presente na constituição da personalidade humana. Revisitando as teorias de Freud ([1913] 1987, [1914] 1987, [1915] 1987, [1920] 1987) e de Rascovsky (1974, 1975), encontramos algumas formulações a respeito do significado do fenômeno e do potencial agressivo que parece ser inerente à natureza humana. Ambos apontam para uma tendência destrutiva pertencente ao homem, e vínculos entre pais e filhos permeados por fantasias agressivas. Portanto, parece que o ser humano constitucionalmente traz consigo um potencial tanto para a vida e para o amor, como também para o ódio e para a destruição, tal como o testemunham as pulsões tanáticas.

Entretanto, deve ser destacado que o fenômeno da violência contra as crianças é complexo e multifatorial. É preciso levar em conta aspectos individuais, sociais, históricos, culturais e econômicos, além dos fatores psicológicos, na determinação dessa forma de violência.

A legislação de proteção da infância e da adolescência evoluiu muito nas últimas décadas, mas essa evolução, por si só, não parece suficiente para impedir a violência contra a criança e o adolescente. Embora constitua um avanço inegável e tenha trazido benefícios para as famílias e para as crianças no Brasil e no mundo, a complexidade do fenômeno demanda ações e intervenções que a legislação apenas não tem sido capaz de assegurar.

O tema da violência tem mobilizado o interesse de teóricos e pesquisadores, identificando-se uma produção significativa com esse foco. Os autores têm se dedicado a descrever as formas de violência sofrida, as características das crianças e dos perpetradores dos maus-tratos cometidos, as notificações em determinados serviços. Muitos teóricos se dedicam a discutir as questões familiares, sociais e históricas associadas à violência contra a criança. Todas essas contribuições são relevantes e auxiliam a iluminar o problema e sua compreensão. Porém, é importante assinalar que parece haver ainda um longo caminho pela frente, sendo que um dos focos que poderia ser profícuo deveria se dirigir às propostas de intervenção sobre o problema e de formulação de políticas públicas e programas sociais que contribuíssem para a sua prevenção.

\section{Referências}

Ariès, P. (2006). História social da criança e da família. Rio de Janeiro: LTC. 
Ariès, P., \& Dubby, G. (1992). História da vida privada do império romano ao ano mil. São Paulo: Cia das Letras.

Brasil. Estatuto da Criança e do Adolescente. (1990). Lei Federal 8.069 de 13 de julho de 1990. Dispõe sobre o Estatuto da Criança e do Adolescente e dá outras providências. Diário Oficial [da] República Federativa do Brasil, Poder Legislativo, Brasília, DF, 27 set. 1990. Recuperado em: 23 jul. 2009, em http://www.planalto.gov.br/ccivil_03/Leis/ L8069.htm

Broad, R. D., \& Wheeler, K. (2006). An adult with childhood medical trauma treated with psychoanalytic psychotherapy and EMDR: A case study. Perspective in Psychiatric Care, 42(2), 95-105.

Caravantes, L. (2000). Violência intrafamiliar em la reforma del sector salud. In A. M. Costa, E. MerchanHamann \& D. Tajer (Org.). Saúde, equidade e gênero: Um desafio para as políticas públicas. Brasília: Editora da UnB.

Carneiro, S. L. M. A. (1999). A violência notificada contra a criança e o adolescente na família: Quando tudo começa em casa. Tese de Doutorado, Pós Graduação Em Saúde Mental, Universidade Estadual de Campinas, Campinas.

Cavenacci, M. (1976). Dialética da família. São Paulo: Brasiliense.

Cecconello, A. M., De Antoni, C., \& Koller, S. H. (2003). Práticas educativas, estilos parentais e abuso físico no contexto familiar. Psicologia em Estudo, 8, 45-54.

Day, V. P., Telles, L. E. B., Zoratto, P. H., Azambuja, M. R. F., Machado, D. A., Silveira, M. B. et al. (2003). Violência doméstica e suas diferentes manifestações. Revista de Psiquiatria do RS, 25(Supl 1), 9-21.

Del Priori, M. (Org.). (2004). História das crianças no Brasil. São Paulo: Contexto.

Faimberg, H. (2001). O mito de Édipo revisitado. In Kaës, R., Faimberg, H., Enriquez, M., \& Barane, J. J. Transmissão da vida psíquica entre gerações (pp. 169-190). São Paulo: Casa do Psicólogo.

Freud, S. ([1913] 1987). Totem e Tabu e outros trabalhos. Rio de Janeiro: Imago.

Freud, S. ([1914] 1987). A história do movimento psicanalítico: Artigos sobre metapsicologia e outros trabalhos. Rio de Janeiro: Imago.
Freud, S. ([1915] 1987). Pulsões e seus destinos. Rio de Janeiro: Imago.

Freud, S. ([1920] 1987). Mais além do princípio do prazer. Rio de Janeiro: Imago.

Fundo das Nações Unidas para a Infância - UNICEF. (2005). Situação da infância brasileira. Relatório Anual. Recuperado em 19 jun. 2008, em http:/ / www. unicef.org.br

Fundo das Nações Unidas para a Infância - UNICEF. (2006). Situação da infância brasileira. Relatório Anual.Recuperado em 19 jun. 2008, em http:/ / www. unicef.org.br

Goel, N. (2000). Ganesha: O elefante perspectivas Deus, Arte e Mitologia. Newsletters Archives, 1, 1-8.

Gomes, R., Junqueira, M. F. P. S., Silva, C. O., \& Junger, W. L. (2002). A abordagem dos maus-tratos contra a criança e o adolescente em uma unidade pública de saúde. Ciência \& Saúde Coletiva, 7(2), 275-283.

Gomes, R., Deslandes, S. F., Veiga, M. M., Bhering, C., \& Santos J. F. C. (2002). Porque as crianças são maltratadas? Explicações para a prática de maus tratos infantis na literatura. Cadernos de Saúde Pública, 18(3), 707-714.

Gomes, R., Silva, C. M. F. P., \& Njaine, K. (1999). Prevenção à violência contra a criança e o adolescente sob a ótica da saúde: um estudo bibliográfico. Ciência $\boldsymbol{\&}$ Saúde Coletiva, 4(4), 171-181.

Grienenberger, J., Kelly, K., \& Slade, A. (2005). Maternal reflective functioning, mother-infant affective communication, and infant attachment: Exploring the link between mental states and observed caregiving behaviour in the intergenerational transmission of attachment. Attachment \& Human Development, 7(3), 299-311.

Guerra, V.N. A. (2001). Violência de pais contra filhos: A tragédia revisitada. São Paulo: Cortez.

Lamanno-Adamo, V. L. C. (1999). Violência doméstica: Uma contribuição da psicanálise. Ciência \& Saúde Coletiva, 4(1), 153-159. Recuperado em 19 jun. 2008, em http://www.scielo.br/pdf/csc/v4n1/ 7138.pdf

Lisboa, C. S. de M., \& Koller, S. H. (2000). Questões de ética na pesquisa com crianças e adolescentes. Aletheia, 11, 59-70. 
Malik, N. M., Ward, K., \& Janczewski, C. (2008). Coordinated community response to family violence: The role of domestic violence organizations. Journal of Interpersonal Violence, 23(7), 933-955.

Maltz, R. S., Zavaschi, M. L., Lewcowicz, A. B., Bugin, A. M., Lahude, D., Suarez, E. M. F., et al. (2008). Poder parental e filicídio: Um estudo multidisciplinar. Revista Brasileira de Psicanálise, 42, 91-102.

Marques, M. T. S. (2000). Melhor interesse da criança: Do subjetivismo ao garantismo. In T. S. Pereira, (Coord.). O Melhor interesse da criança: Um debate interdisciplinar (pp. 467-494). Rio de Janeiro: Renovar.

McDonald, R., Jouriles, E. N., Briggs-Gowan, M. J., Rosenfield, D., \& Carter, A. S. (2007). Violence toward a family member, angry adult conflict, and child adjustment difficulties: Relations in families with 1 - to 3-year-old children. Journal of Family Psychoogy, 21(2), 176-184.

Minayo, M. C. S. (2001). Violência contra crianças e adolescentes: Questão social, questäo de saúde. Revista Brasileira de Saúde Materno infantil, 1(2), 91-102.

Neves, A. S., \& Romanelli, G. A. (2006). Violênciadoméstica e os desafios da compreensão interdisciplinar. Estudos de Psicologia, 23(3), 299-306.

Pereira, T. S. (Coord.). (2000). O Melhor interesse da criança: Um debate interdisciplinar. Rio de Janeiro: Renovar.

Pesce, R. (2009). Violência familiar e comportamento agressivo e transgressor na infância: Uma revisão de literatura. Ciência \& Saúde Coletiva, 14(2), 507-519.

Pires, A. L. D., \& Miyazaki, M. C. O. S. (2005). Maus-tratos contra crianças e adolescentes: revisão da literatura para profissionais da saúde. Arquivo de Ciências da Saúde, 12, 42-49.

Postman, N. (1999). O desaparecimento da infância. Rio de Janeiro: Graphia.

Ramires, V. R. R. (1997). O exercício da paternidade hoje. Rio de Janeiro: Rosa dos Ventos.

Ramires, V. R. R., \& Rodrigues, M. A. (2003). As transições familiares e o melhor interesse da criança: As perspectivas do Direito e da Psicologia. Estudos Jurídicos, 36(97), 211-242.
Rascovsky, A. (1974). O filicídio. Rio de Janeiro: Artenova.

Rascovsky, A. (1975). La matanza de los hijos y otros ensayos. Buenos Aires: Kargieman.

Reyes, M. E. F. (2003). Maltrato infantil. Un problema de todos. Revista Cubana de Medicina General Integral. Recuperado em 19 jun. 2008, em www.scielo.sld.cu/scielo.php?script $=$ sci_ arttext\&pid $=$ S0864-21252003000100009\&lng=es \&nrm=iso

Romaro, R. A., \& Capitão, C. G. (2007). A violência doméstica contra crianças e adolescentes. Psicol Am Lat, 9. Recuperado em 19 jun. 2008, em http:/ / pepsic.bvs-psi.org/ scielo.php?pid=S1870350X2007000100002\&script $=$ sci_arttext

Sacramento, L. T., \& Rezende, M. M. (2006). Violên cias: Lembrando alguns conceitos. Aletheia, 24, 95-104.

Santoro, M. J. (2002). Maus-tratos contra crianças e adolescentes: Um fenômeno antigo e sempre atual. Pediatria Moderna, 6, 279-283.

Schechter, D. S., Coots, T., Zeanah, C. H., Davies, M., Coates, S. W., Trabka, K. A. et al. (2005). Maternal mental representations of the child in an inner-city clinical sample: Violence-related posttraumatic stress and reflective functioning. Attachment \& Human Development, 7(3), 313-331.

Schraiber, L. B., D’Oliveira, A. F. P. L., \& Couto, M. T. (2006). Violência e saúde: Estudos científicos recentes. Revista de Saúde Publica, 40, 112-120.

Silva, L. L., Coelho, E. B. S., \& Caponi, S. N. C. (2007). Violência silenciosa: Violência pspsicológica como condição da violência física doméstica. Interface Comunic Saúde, Educ, 11, 93-103.

Souza, M. L. R. (2005). Violência. São Paulo: Casa do Psicólogo.

Sternberg, K. J., Lamb, M. E., Guterman, E., \& Abbott, C. B. (2006). Effects of early and later family violence on children's behavior problems and depression: A longitudinal, multi-informant perspective. Child Abuse \& Neglect, 30(3), 283-306.

Tardivo, L. S. P. C., Pinto Jr., A. A., \& Santos, M. R. (2005). Avaliação psicológica das vítimas de violência doméstica por meio do teste das fábulas de Düss. PsicRevista de Psicologia da Vetor Editora, 6, 59-66. 
Telles, L. E. B., Soroka, P., \& Menezes, R. S. (2008). Filicídio: De Medeia a Maria. Revista de Psiquiatria do RS, 30, 81-84.

Weber, L. N. D., Viezzer, A. P., Brandenburg, O. J., \& Zocche, C. R. E. (2002). Famílias que maltratam: Uma tentativa de socialização pela violência. PsicoUSF, 7(2), 163-173.

Weber, L. N. D., Viezzer, A. P., \& Brandenburg, O. J. (2004). O uso de palmadas e surras como prática educativa. Estudos de Psicologia, 9(2), 227-237.

Recebido: 29/09/2010

Received: 09/29/2010

Aprovado: 15/04/2011

Approved: 04/15/2011 